\title{
Redirecting traditional professional values to support safety: changing organisational culture in health care
}

\section{J S Carroll, M A Quijada}

Qual Saf Health Care 2004;13(Suppl II):ii16-ii21. doi: 10.1136/qshc.2003.009514

Professionals in healthcare organisations who seek to enhance safety and quality in an increasingly demanding industry environment often identify culture as a barrier to change. The cultural focus on individual autonomy, for example, seems to conflict with desired norms of teamwork, problem reporting, and learning. We offer a definition and explication of why culture is important to change efforts. A cultural analysis of health care suggests professional values that can be redirected to support change. We offer examples of organisations that drew upon cultural strengths to create new ways of working and gradually shifted the culture.

See end of article for authors' affiliations

Correspondence to: Professor J S Carroll, MIT Sloan School of Management, 50 Memorial Drive Cambridge, MA 02142, USA; jcarroll@mit.edu
$\mathrm{T}$ he recent movements in health care toward enhanced patient safety and quality of care are directed at systemic changes beyond increased technical proficiency and financial efficiency. We agree that

"quality problems occur typically not because of a failure of goodwill, knowledge, effort, or resources devoted to health care, but because of fundamental shortcomings in the ways care is organised".'

Health care is delivered by individuals with personal and professional identities who work within and across complex organisations structured by our economic-political-legal system. Fundamental changes, such as those advocated by the Institute of Medicine reports ${ }^{2}$ and the Institute for Healthcare Improvement (http:// www.ihi.org), must address behaviour, systems, and the cultural assumptions that underlie and reinforce existing behaviours and structures in order to be successful and enduring. Our purpose is to present an approach to culture change that emphasises working with existing cultural strengths to address practical problems in new ways that will gradually shift cultural assumptions and values.

\section{PRESSURES ON THE HEALTHCARE SYSTEM}

\footnotetext{
"Searching for one word to describe the state of mind of the physician in the United States today, we might choose beleaguered." ${ }^{\prime 3}$
}

Depressing litany of challenges affects everyone involved in the healthcare industry: malpractice insurance premiums, nursing shortages, managed care, aging populations with higher levels of acuity, shortages of hospital beds, media frenzy around medical errors, confidentiality of patient information, automated records, and prescriptions. The golden age of medicine ${ }^{4}$ is over. Economic pressures and new technologies have shifted the balance of power between physicians, technicians, nurses, hospitals, and insurers. ${ }^{56}$ Where health care was once a high calling, it is now a regulated business whose customers want permanent good health while payers insist on limiting costs and curtailing professional discretion.

Healthcare organisations have always been complex, but efficiency demands have strained the interdependencies in the system. With less slack and more rapidly scripted processes, each delay cascades through the system to create other problems. Each step in the delivery of care, including support steps such as intake and discharge, billing, and transport of patients, can create delay and confusion, even error. Such pressures may be the stimulus for beneficial innovation, as necessity spawns invention and traditional ways of working are reengineered for quality and efficiency, or they may simply create ad hoc workarounds with risky side effects, interpersonal conflicts, and plummeting morale. Healthcare professionals have barely enough time and energy to cope with daily problems, leaving few resources for innovation and fundamental change. ${ }^{7}$

\section{CULTURE AND CHANGE}

The culture of health care is distinctive; some aspects are readily apparent to outsiders. Popular television programmes show hospitals as fast paced, intense, high stake, and very personal settings. Doctors, nurses, technicians, administrators, pharmacists, scientist researchers, students, patients, families, lawyers, emergency workers, and maintenance workers collide under near battlefield conditions. We see the long hours, the high stress, the demanding training of students, the status hierarchies, the interdependence of professional specialties, the decisions made under uncertainty, and the challenges of balancing excellent care, discovery of new knowledge, and efficient use of time and money. This has been portrayed as high drama in $E R$ and as low comedy in Scrubs.

For our purposes, a good everyday definition of culture is the way we do things around here and why we do them. This definition emphasises 
both visible behaviours and the more subtle values and assumptions underlying them. Edgar Schein, one of the seminal figures in the study of organisational culture, articulated the three level conceptualisation of culture ${ }^{8}$ portrayed in fig 1. At the top or surface level are the observable behaviours and artifacts of the organisation. This is what a television camera or documentary crew would capture in a hospital, a doctor's office, a community clinic, a medical research laboratory, an insurance company, or any other piece of the healthcare system. An observer could extract patterns of behaviour or norms, but it would be difficult to understand what is happening without talking to people about the meaning of these activities. Schein's second level of culture comprises the beliefs and values that participants espouse, what they are willing and able to verbalise. However, as we all know, our behaviours and our beliefs and justifications are sometimes inconsistent. Although there may be mission statements, signs on the walls, and administrative speeches about quality of patient care, the reality is that quality is challenged every day by speed and cost concerns and unwieldy systems. Interns, doctors, and nurses may not readily admit that they work undocumented hours (beyond what is allowed in guidelines) in order to get their job done and deliver the kind of care they believe is necessary. ${ }^{9}$ These contradictions are captured in Schein's third and deepest level of culture: underlying assumptions, often taken for granted and unarticulated, that have developed over time through successful collective problem solving. This deepest level of culture is just as real as the other levels, and often more important for understanding why things happen or fail to happen.

It is important to recognise that cultures vary greatly in their uniformity or fragmentation, and there is no right or wrong amount of uniformity or strength. ${ }^{8}{ }^{10}$ A hospital, for example, is not a single culture but rather a fragmented collection of occupational cultures ${ }^{11}$ such as medicine, nursing, and management (and subcultures within, such as surgery, anaesthesiology, pharmacy, finance, and marketing). Within these occupational groups there are international cultures, such as Jamaican nurses, Salvadoran cleaning crews, and Irish maintenance workers and, within the total medical centre unit, the local culture of being in Chicago, Boston, or Miami. Edmondson found that even similar work groups in the same nursing unit or operating room can have different cultures based around leadership style. ${ }^{7}$ A strong organisation leader may try to meld those bits and pieces into a single identity and culture, or a crisis may bring everyone together with common purpose and force some cultural blending in answer to the crisis, but the individuals and groups are likely to retain diverse cultural elements within a more or less uniform organisational culture.
Change that is not rooted in culture can be ephemeral, and real long term culture change takes years. People resist changes that undermine their hard won expertise, status, identity, habits, and understandings. ${ }^{12}$ New senior managers usually try to put their stamp on their organisation by making a new mission statement, changing the organisation chart, putting their own people in top positions, and changing performance measures and incentives. There may even be signs of desired change in the form of reports from middle management or statistics that are moving in the right direction. Then progress seems to slow, momentum is lost, and attention shifts to other issues. At the front lines, people are doing much the same thing as before, equally distant from and cynical about senior management. People may say things like, "we were told patient safety was important, but the first person to report a near miss was punished, and then they didn't purchase the new equipment because it was too expensive, so we got the message that it was business as usual".

Culture cannot easily be mandated-it develops over time as a successful adaptation to conditions, bringing desired results and defining desired norms and values. It is tempting for senior managers just to announce new behaviours or new values, but if they do not clearly specify what is desired and how it connects to meaningful consequences (both personal rewards and punishments and value congruent results such as better patient outcomes), they will not give people a chance to learn that the new behaviours work better than current practices. This process is much more likely to succeed if key individuals are involved in helping to design new ways of doing things that solve real problems and thereby engage their internal motivation. Once enough people realise that things work better, the values that lay behind the mandated new behaviours become more accepted, and new assumptions arise to support how these behaviours are "the way we do things around here".

Schein suggests a variety of strategies for culture change. ${ }^{13}$ In one strategy, leaders are imported from another culture in the hope that they will place their stamp on the organisation through coercively mandating behavioural changes. For example, nuclear power plants that get in trouble with regulators have a pattern of hiring Navy admirals into senior management positions on the assumption that the Navy has an effective and disciplined way of doing things and the admiral will be able to make the plant more Navy-like. However, the research literature suggests that such a culture war is successful only if the new leader gains credibility with the employees and mandates changes that make some sense in the present culture. ${ }^{14}$ Health care faces the additional obstacle that there is no clear role model culture to emulate. Does it make sense for hospitals to hire from the Navy or the
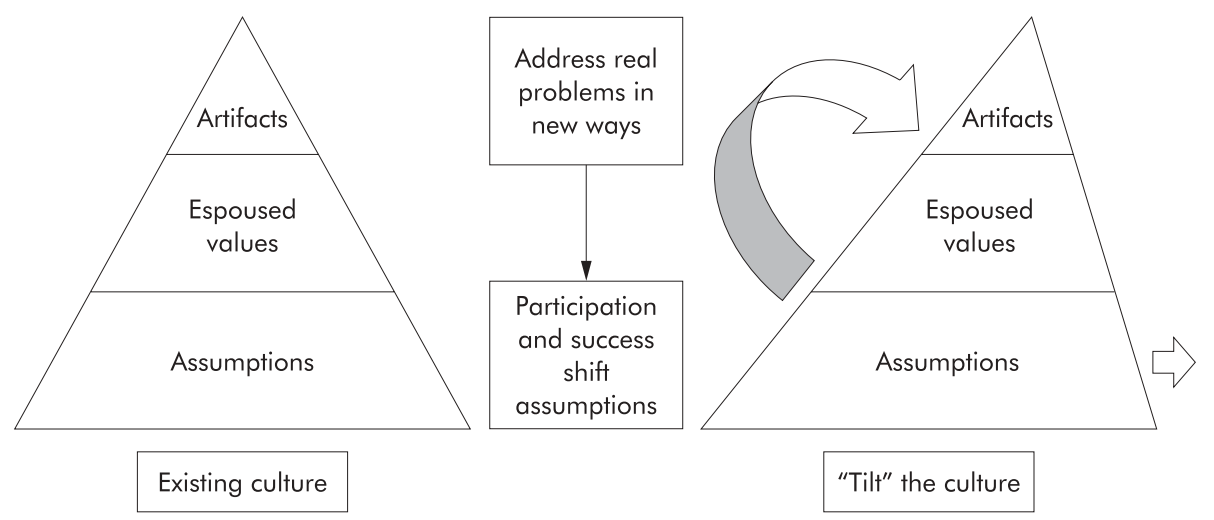

Figure 1 Culture change by "tilting" the culture. 
airlines? ${ }^{15}$ Could such people function effectively in the culture of health care: do they have the necessary technical knowledge and familiarity with the work? Or, should we cannibalise other healthcare organisations that are considered progressive and successful by hiring away their leaders?

An alternative strategy focuses on more cooperative change that we believe could be advantageous for health care. Schein suggests that every culture has strengths that can be drawn upon and reframed to be supportive of the desired changes. In this way the new behaviours and values can be tied to existing assumptions and values, given legitimacy, and made more acceptable and less threatening. Over time, as these new behaviours are tried out, and if people recognise that they are working well to bring desired results, new assumptions arise to articulate the cultural lessons learned. In the righthand panel of fig 1 , we represent this as a curved arrow, using cultural elements to design new behaviours (artifacts) that shifts or tilts the top of the pyramid. As the surface level of culture shifts, while the connections to deeper levels are retained, the deeper levels will gradually shift as well (the second, smaller arrow in the figure) as people reshape their own culture to give meaning to the links between behaviours and values. Cooperider offers a related idea in arguing for appreciative inquiry, that is, assessing strengths and sources of resiliency rather than focusing on deficiencies and problems. ${ }^{16}$

\section{AN EXAMPLE OF "TILTING" THE CULTURE FROM ANOTHER INDUSTRY}

In the mid 1990s the Millstone Nuclear Power Station in Connecticut was forced to cease operations by the US Nuclear Regulatory Commission (NRC) because of a variety of problems, although management insisted that they were running a safe and effective operation. Employees within Millstone who had raised questions about quality and safety had reportedly been pressured by management to remain silent. The founding culture of Millstone, which had focused on technical excellence, had been thrust underground when financial crises in the 1980s made heroes out of those who got things done at low cost, even if it meant starting the newest unit with a long list of work to be done. An interviewee at Millstone ${ }^{17}$ labelled the management culture as "male...militaristic_control and command". The NRC had been promised by Millstone that there would be changes, but Millstone had not delivered. A few engineers who never bought into the current culture became whistleblowers to the NRC and the media. The NRC then acted to force change, requiring not only technical changes but also the creation of a "safety conscious work environment" that would ensure a proper response to employee concerns.

The Board of Trustees' first step was to hire a new senior manager (CEO-Nuclear) to be in charge of Millstone (and the other nuclear plants of this company). He moved swiftly to communicate his values-high standards, openness, and honesty; commitment to do what was right; and two way communication-through numerous meetings and pronouncements and to solidify his management team with changes including the hiring of a Navy Admiral for Oversight (Quality) and the Admiral's former Chief of Staff to manage the Employee Concerns Program, intended to provide a safe way for employees to communicate about issues. However, the CEO-Nuclear admitted he had "never encountered a culture as broken," where management actions were regarded automatically with suspicion and distrust. As a result, changes were moving very slowly at first, because employees were reluctant to take the risks that change requires.

Trust developed over time because senior management created opportunities for broad participation and personal transformations in an environment that accepted honest mistakes. For example, the CEO-Nuclear put the operations vice president in charge of the safety conscious work experience initiative. This vice president was a bright and articulate engineer but also a typical old style manager: he described himself as weary of "whiners" and said that "a lot of people were scared of me, although I knew I wouldn't do anything wrong". He admitted that he was just "going through the motions...I didn't believe anyone would harass someone who brought forth safety concerns...After all, I live near here". Yet several months later, when two contractors were terminated for alleged poor performance, the Director of the Employee Concerns Program immediately protested (and the CEO-Nuclear reversed the termination pending a review), and a prompt investigation provided evidence that the terminations had been improper, the operations vice president realised "it was one of those moments your perception changes...a watershed for me". In response to this event, senior management created an Executive Review Board (ERB) to examine any disciplinary actions, but its scope broadened to become a forum for discussion and learning about difficult management issues.

Over time, through continual communication, creation of new forums for discussion, encouragement of contributions from all levels of the workforce, training of all managers, and willingness to admit error and vulnerability (a major culture change since managers were evaluated on having no problems), participation and initiative spread through the organisation. Of course, some managers could not change and had to be moved aside, but this was done fairly and openly. As employees came to believe that management was doing what was best for the plant and for their jobs, they began to contribute their ideas and efforts to the common problem of rebuilding Millstone. This process took two years, but resulted in sufficient change for the NRC to agree that a safety conscious work environment had been established and demonstrated to its satisfaction and to authorise restart of one of the nuclear power units (and a year later, a second unit was restarted).

Although these actions and changes targeted behaviours and espoused values, without conscious planning they engaged deeper cultural values and assumptions. Millstone's traditional cultural strengths of excellence, professional integrity, and safety, which had been in a kind of culture war with cost issues and the assumption that good managers had no problems, became linked in support of new values of openness and mutual respect. For example, the meaning of excellence had been based on assumptions such as "excellent managers have no problems and excellent engineers know everything they need to know". Through training, role models, and experience with many months of change at Millstone, the meaning of excellence shifted to encompass new behaviours connecting to assumptions such "as excellent managers want to hear about problems and surprises in order to prevent more serious problems" and "excellent engineers use their knowledge to constantly learn and improve". Professional integrity shifted from "we have deep knowledge in our professional field of training" to include "professionals speak up in order to keep everyone informed" and "professionals listen to and learn from other professionals in order to enhance safety".

\section{A CULTURAL ANALYSIS OF HEALTH CARE}

The Institute of Medicine's report Crossing the quality chasm, gives a good summary of some of the cultural rules or patterns of behaviour that characterise medicine today, along with suggestions for tomorrow's desired rules. ${ }^{1}$ As shown in table 1 , these rules are stated as a mixture of behaviours (professionals control care) and espoused values (secrecy is necessary). They focus on the current importance of 
autonomy, professionalism, individuality, and secrecy and the need for openness, patient centered care, teamwork, and system thinking. It is tempting to infer that health care must mandate new rules and thereby change its culture. However, what is missing are the assumptions connecting these rules to each other and to desired outcomes-for example, professionals control care because decision making is based on training and experience to give the best care to each unique patient and therefore preference is given to professional roles over the system. The new rules have to be embedded in shared assumptions, such as knowledge is shared and information flows freely because different caregivers and the patient and family must all contribute to successful care, which is customised according to patient needs and values. In order to change the rules, we must therefore search within the current culture for elements that can be retained, strengthened, reframed, and linked to new desired behaviours and values. New behaviours have to be tried out and shown to be effective, so that new assumptions will emerge to embed these lessons in the culture.

Autonomy, the assumption that the professional practitioner must have the right to make his or her own decisions, is one of the cornerstones of the medical culture (but not necessarily to all professional and occupational cultures within health care). In many hospitals, doctors are not even employees of the hospital but rather individual or small group practitioners who have privileges to work at one or more hospitals. ${ }^{18}$ Even in the operating room, it is not clear who is in charge of an operation: the surgeon is responsible for the operation but the anaesthesiologist is responsible for the patient, so these autonomous professionals must cooperate, which usually means the anaesthesiologist defers to the surgeon, but not always. Lack of role clarity around leadership can be a source of stress and even error. ${ }^{5}$

Autonomy, by itself, can be a cultural strength. For decades, if not centuries, the wellbeing of patients has depended on the skills of the individual practitioner. Training, licensing rules, folklore, stories about heroes, honoured role models, and personal experience reinforce the assumption that individual skill is the single most important determinant of healthcare outcomes. The traditional way to avoid medical error is to hire highly qualified doctors and nurses who will avoid mistakes. ${ }^{9}$ Doctors take initiative, make difficult decisions rapidly under great stress, take responsibility for their own learning, and feel personally engaged in their work. Nurses are expected to solve any issues that may arise in order to avoid disrupting their managers or the physicians. ${ }^{9}$

\section{Table 1 Simple rules for the 21 st century health care} system

\begin{tabular}{|c|c|}
\hline Current approach & New rule \\
\hline Care is based primarily on visits & $\begin{array}{l}\text { Care is based on continuous healing } \\
\text { relationships }\end{array}$ \\
\hline $\begin{array}{l}\text { Professional autonomy drives } \\
\text { variability }\end{array}$ & $\begin{array}{l}\text { Care is customised according to } \\
\text { patient needs and values }\end{array}$ \\
\hline $\begin{array}{l}\text { Professionals control care } \\
\text { Information is a record }\end{array}$ & $\begin{array}{l}\text { The patient is the source of control } \\
\text { Knowledge is shared and } \\
\text { information flows freely }\end{array}$ \\
\hline $\begin{array}{l}\text { Decision making is based on } \\
\text { training and experience }\end{array}$ & Decision making is evidence-based \\
\hline $\begin{array}{l}\text { Do no harm is an individual } \\
\text { responsibility }\end{array}$ & Safety is a system property \\
\hline Secrecy is necessary & Transparency is necessary \\
\hline The system reacts to needs & Needs are anticipated \\
\hline Cost reduction is sought & Waste is continuously decreased \\
\hline $\begin{array}{l}\text { Preference is given to } \\
\text { professional roles over the system }\end{array}$ & $\begin{array}{l}\text { Cooperation among clinicians is a } \\
\text { priority }\end{array}$ \\
\hline Adapted fror & \\
\hline
\end{tabular}

But autonomy can also be a weakness. For example, doctors assume they have to be "iron men" who can do everything themselves, learn everything themselves, and work long hours without sleep. No one, including colleagues, feels comfortable telling a physician how to practice medicine. ${ }^{9}$ It is therefore challenging to standardise practices that vary by region, hospital, and physician, upwards of $85 \%$ of which have not been tested empirically. ${ }^{19}$ If among all of the skills for improvement, the most crucial one may be the skill to cooperate across traditional boundaries, ${ }^{20}$ then how do we change individualistic behaviour into being part of the team as opposed to being the sole decision maker. ${ }^{21}$ Equally troubling, autonomy is often understood as not asking for help or admitting weakness. When nurses do ask for help, they ask people they are close to rather than those best equipped to solve the problem. ${ }^{9}$ Autonomy easily becomes attached to secrecy when people assume that speaking up will bring sanctions and outside interference in their practice. ${ }^{22}$

Rather than combat the importance of autonomy in health care, we believe it is necessary to modify the way it is understood and linked to other values and assumptions. Indeed, the sense of personal responsibility and willingness to take initiative may often keep a dysfunctional system from collapsing completely, and will be critical to overcome fear of change. The current understanding of autonomy is closely linked to status and power: in any situation, it is those at the top of the status hierarchy who have autonomy while others are there to assist. Can we reinterpret autonomy, building in understandings from various medical and nursing specialties; linking it to caring, excellence, and professionalism; and extending it to more people in order to encourage speaking up, teamwork, and shared purpose?

An interesting example of culture change in health care that started from senior leadership was the shift toward patient safety at Minneapolis Children's Hospitals and Clinics championed by Julie Morath, who became COO in 1999. ${ }^{23}$ She framed the following vision for patient safety:

\section{"The culture of health care must be one of everyone working together to understand safety, identify risks, and report them without fear of blame. We must look at ways of changing the whole system when we manage to zero defects."}

While vision and guiding ideas can create a sense of shared purpose, shape thinking, and orient the organisation toward particular values and criteria for success, these have to be connected to people's current understandings and exemplified by concrete new ways of working. ${ }^{24}$ Morath created structures such as the Patient Safety Steering Committee to provide resources and venues for cross-disciplinary participation, allowing people to work together to learn how to solve common problems in terms of the new values. Leaders acted as role models and teachers to help demonstrate and interpret new behaviours. Brock Nelson, CEO of Children's Hospitals and Clinics, openly described his personal epiphany in being able to enact a new policy of disclosing more information and personally apologising to a family that had lost a teenage child who had initially been misdiagnosed. This helped to balance the medical culture of infallibility, where acknowledging any failure can meet with resistance among physicians and managers for whom success is the only acceptable result. ${ }^{25}$

A very different example of culture change illustrates the variety of subcultures in health care and the initiation of change within subcultures. In a study of implementation of new technology for minimally invasive cardiac surgery at 16 
Table 2 Healthcare cultural resources

\begin{tabular}{|c|c|}
\hline Desired cultural elements & Existing cultural strengths \\
\hline $\begin{array}{l}\text { Informed-each healthcare } \\
\text { contributor has current } \\
\text { knowledge of safety factors } \\
\text { Reporting-everyone is able } \\
\text { to speak up about problems } \\
\text { and surprises } \\
\text { Just-everyone feels fairly } \\
\text { treated by everyone else, for } \\
\text { example not unfairly blamed } \\
\text { Learning-there is more to } \\
\text { know, so we are always } \\
\text { learning, even from failure } \\
\text { Teamwork-health care } \\
\text { demands teamwork from } \\
\text { complementary professionals } \\
\text { Quality-we measure our } \\
\text { individual and collective } \\
\text { performance in order to improve }\end{array}$ & $\begin{array}{l}\text { Scientific inquiry-healthcare } \\
\text { practice is more effective when based } \\
\text { on evidence } \\
\text { Self-criticism-we learn faster by } \\
\text { attending to every detail of our } \\
\text { performance } \\
\text { Responsibility-the individual is } \\
\text { responsible for all aspects of patient } \\
\text { care } \\
\text { Training-we learn by repeated } \\
\text { practice and feedback from } \\
\text { experienced mentors } \\
\text { Caring-health care is a helping } \\
\text { profession that focuses on people's } \\
\text { wellbeing } \\
\text { Excellence-we want to be the best at } \\
\text { what we do, and be recognised for it } \\
\text { Dedication-excellence demands } \\
\text { long hours and selfless focus on the } \\
\text { work }\end{array}$ \\
\hline
\end{tabular}

hospitals, it was not high level management support that was decisive in successful implementation, but instead the way the surgical team leaders fostered an atmosphere of learning including acknowledgment of doubt, encouragement of communication, and real time team learning. ${ }^{26}$ Yet we might guess that these cultural innovations would only spread across teams if the reasons for better performance were shared and understood and other surgical team leaders had support to try new behaviours.

In table 2 we offer some suggestions for cultural elements that could be strengthened in health care, drawing on Reason's ideas about safety culture and the Institute of Medicine reports. ${ }^{27}$ These are paired with existing cultural strengths that could be drawn upon for change. For example, in trying to create a reporting culture where everyone is comfortable raising concerns, even in the face of status hierarchies (as in Edmondson's example of operating room teams or the Millstone nuclear power station), we could draw on cultural elements of scientific empiricism (facts are important), responsibility, caring (about patient outcomes), self-criticism, and excellence. However, such an argument in the abstract is not of much use unless it is attached to a real change effort, such as developing a near-miss reporting system and experiencing the challenges and benefits it would provide (including the benefits of new working relationships among different groups involved in the new system). Beer and colleagues report that change programmes that focus on attitudes often fail. ${ }^{28}$ But energy can be directed toward change by drawing on existing attitudes and values, as the leadership of Dana-Farber Cancer Institute did when they announced, following Betsy Lehman's tragic death from a cancer treatment overdose, that they would become a national leader in safety just as they had become a national leader in research, drawing on their cultural values of excellence and scientific inquiry. ${ }^{29}$ Of course, these are only the beginnings of ideas and examples for an approach to culture change.

Each hospital or other healthcare organisation has to find its own way to move forward. Each organisation starts out with different strengths and opportunities, as well as challenges. As Schein points out, ${ }^{8}$ it is difficult and often counterproductive to work on culture change by directly trying to design the new culture in the abstract. Instead, it is possible to create opportunities for people to work together on real problems in ways that draw on cultural strengths and allow new ways of working to emerge, be experimented with, and become part of the new culture. Although attempting a cultural analysis disconnected from specific change issues may not be helpful, it may be useful to treat culture change examples from other organisations as cases that can prompt an open exchange of viewpoints across disciplines and units regarding the relevance of those cases for their problems and their organisation (Schein EH, personal communication, 2004). It takes creativity to turn that understanding into an action plan, and it takes real discipline to enact new behaviours and consistently communicate what is happening in new terms. But as shown by the Children's Hospitals and Millstone Station examples, senior managers can build on existing cultural strengths to start the process, and support will emerge over time, although culture change takes considerable time.

\section{SUGGESTIONS AND CONCLUSIONS}

Enduring change in health care requires a change in culture, but that change is unlikely to come about by directly attacking the existing culture (see box 1 for lessons for culture change). Instead, an understanding of the nature, sources, and functioning of culture leads us to suggest that health care has deep cultural strengths that can be built upon to support and reinforce change. We sketch only the beginnings of an analysis of culture in health care, partly because every healthcare organisation is different and therefore has to work with their own cultural elements in the context of practical change efforts. But there are themes that are likely to emerge repeatedly, such as the reinterpretation of professional autonomy and individuality to support teamwork, reporting of problems, and learning. Autonomy and individual responsibility are tremendous strengths that should not be dismissed or replaced, but rather appreciated for what they offer. If we dig deeper into the culture, we can address the assumptions that give meaning to autonomy and individuality and connect these concepts to actions and values. Leaders can then begin to reframe new actions in

\section{Box 1 Lessons for culture change}

- Culture is the way we do things around here and why we do it that way.

- Positive long lasting change needs to be consistent with culture.

- Rather than oppose the existing culture, it may be more effective to build on existing cultural strengths and gradually shift or tilt the culture.

- Such a strategy requires opportunities to engage broad participation in change efforts directed at real problems that people care about; by creating and trying out new behaviours, new cultural assumptions and values will emerge.

- Remember that leaders go first as role models and risk takers.

- Senior leaders can provide resources and protection for risk taking.

- Leaders at all levels can reinterpret actions and values in new ways that connect with existing cultural strengths.

- Leaders may have to mandate new goals and values, and even coerce new behaviours, but linking these efforts to cultural strengths minimises resistance.

- Admit mistakes and doubt; we are all learning.

- Change takes time; be persistent. 
terms that link to existing concepts but gradually tilt the balance of cultural elements to shift actions, values, and underlying assumptions.

\section{ACKNOWLEDGEMENTS}

Our thanks to Ed Schein for his comments and contributions and to Paul Barach, Amy Edmondson, Kate Kellogg, Jenny Rudolph, Robert Simon, Bob Wears, and anonymous reviewers for their help.

\section{Authors' affiliations}

J S Carroll, M A Quijada, MIT Sloan School of Management, Massachusetts, USA

\section{REFERENCES}

1 Institute of Medicine. Crossing the quality chasm: a new health system for the 21 st century. Washington, DC: National Academy Press, 2001:25.

2 Institute of Medicine. To err is human: building a safer health system. In: Kohn LT, Corrigan JM, Donaldson MS, eds. Washington, DC: National Academy Press, 2000.

3 Berwick DM, Nolan TW. Physicians as leaders in improving health care: a new series in Annals of Internal Medicine. Ann Intern Med 1998; 128:289-92.

4 Hafferty F, Light D. Professional dynamics and the changing nature of medical work. J Health Soc Behav 1995;35:132-153.

5 Millman M. The unkindest cut: life in the backrooms of medicine. New York: Morrow Quill, 1977.

6 Barley SR. Technology as an occasion for structuring: evidence form observations of CT scanners and the social order of radiology departments. Adm Sci Q 2001;31:78-108.

7 Edmondson AC. Learning from failure in health care: frequent opportunities, pervasive barriers. Qual Safe Health Care in press.

8 Schein EH. Organizational culture and leadership. 2nd edn. San Francisco: Jossey-Bass, 1992

9 Tucker A, Edmondson AC. Why hospitals don't learn from failures: organizational and psychological dynamics that inhibit system change. Calif Manage Rev 2003;45:55.

10 Martin J. Cultures in organizations: three perspectives. New York: Oxford, 1992.
11 Van Maanen J, Barley SR. Occupational communities: culture and control in organizations. In: Staw BM, Cummings LL, eds. Research in organizational behavior, Vol. 6. Greenwich, CT: JAl, 1984.

12 Kanter RM, Stein B, Jick T. The challenge of organizational change: how companies experience it and leaders guide it. In: Beckhardt R, Pritchard W, eds. Changing the essence: the art of creating and leading fundamental change in organizations. New York: Free Press, 1992.

13 O'Reilly CA, Chatman JA. Culture as social control: corporations, cults, and commitment. Res Org Behav 1996;18:157-200.

14 Dyer WG Jr. Culture change in family firms. San Francisco: Jossey-Bass, 1986.

15 Helmreich RL, Merritt AC. Culture at work in aviation and medicine: National, organizational and professional influences. Brookfield, VT: Ashgate, 1998.

16 Cooperider DL, Sorensen PF Jr, Whitney D, et al, eds. Appreviation inquiry: rethinking human organization toward a positive theory of change. Champaign, IL: Stipes, 2000.

17 Carroll JS, Hatakenaka S. Driving organizational change in the midst of crisis. MTS Manage Rev 2001:42:70-9.

18 Adler P, Riley P, Kwon S, et al. Performance improvement capability: keys to accelerating performance improvement in hospitals. Calif Manage Rev 2003;45: 12 .

19 Millenson ML. Demanding medical excellence. Chicago: University Chicago Press, 1997.

20 Berwick DM, Nolan TW. Physicians as leaders in improving health care. Ann Intern Med 1998; 128:289-92

21 Parker DL, Wertheimer DS. Incorporating internal medicine residents into an interdisciplinary geriatric assessment team. Acad Med 1997;72:451.

22 Edmondson A. Speaking up in the operating room: how team leaders promote learning in interdisciplinary action teams. J Manage Stud 2003:40:1419-52

23 Edmondson A, Roberto M, Tucker A. Children's hospitals and clinics. HBS Case \#9-302-050. Boston, MA: Harvard Business School Press, 2001.

24 Schein EH. The corporate culture survival guide. San Francisco: Jossey-Bass, 1999.

25 Berwick DM. Developing and testing changes in delivery of care. Ann Intern Med 1998;128:651-6.

26 Pisano GP, Bohmer RMJ, Edmondson AC. Organizational differences in rates of learning: evidence from the adoption of minimally invasive cardiac surgery. Manage Sci 2001;47:752-68.

27 Reason J. Managing the risks of organizational accidents. Brookfield, VT Ashgate, 1997.

28 Beer M, Eisenstat RA, Spector B. Why change programs don't produce change. Harv Bus Rev 1990:68:158-66.

29 Bohmer RMJ. The Dana-Farber Cancer Institute. Teaching Note 5-603-092. Boston, MA: Harvard Business School, 2003. 